\title{
NOVAS ESPÉCIES DE ACHYROCLINE (LESS.) DC. (ASTERACEAE) PARA O BRASIL ${ }^{1}$
}

\author{
LEONARDO PAZ DEBLE² JOSÉ NEWTON CARDOSO MARCHIORI ${ }^{3}$
}

\section{RESUMO}

Duas novas espécies brasileiras de Achyrocline (Less.) DC. são descritas e ilustradas: A. ribasiana Deble \& Marchiori, do Espírito Santo, e A. tombadorensis Deble \& Marchiori, da Bahia.

Palavras-chave: Achyrocline ribasiana, Achyrocline tombadorensis, novas espécies, Asteraceae.

\section{ABSTRACT}

Two new brazilian species of Achyrocline (Less.) DC. are presently described and illustrated: A. ribasiana Deble \& Marchiori, native in the State of Espírito Santo, and A. tombadorensis Deble \& Marchiori, from the State of Bahia.

Key words: Achyrocline ribasiana, Achyrocline tombadorensis, new species, Asteraceae.

\section{INTRODUÇÃO}

O gênero Achyrocline (Less.) DC. reúne cerca de 45 espécies, em sua maioria da América do Sul, ocorrendo apenas cinco na América Central e quatro na África. Relacionado ao gênero Pseudognaphalium Kirp., difere, deste, por apresentar invólucro cilíndrico ou oblongo, com flores femininas dispostas em uma única série. Com as presentes descrições, eleva-se a dezoito o número de espécies representadas no Brasil e que se distribuem, principalmente, nos Estados do Rio Grande do Sul, Rio de Janeiro, Espírito Santo, Bahia e Minas Gerais.

\section{DESCRIÇÃO DAS ESPÉCIES}

\section{Achyrocline ribasiana Deble \& Marchiori sp. nov. ${ }^{4}$}

Suffrutex ramosus, lignosus; caulibus ascendentibus, teretibus, ramosis, dense tomentosis, $20-30 \mathrm{~cm}$ longis. Folia alterna (internodiis $1-5 \mathrm{~cm}$ longis), sessilia; laminis lanceolatis, integris, superne laxe lanoso-tomentosis, inferne dense lanoso-tomentosis, apice acuminatis, basi longo-attenuatis, 3-9 cm longa, 0,3-1 cm lata. Capitula multa, cymoso-paniculata glomerata disposita. Involucrum oblongum, stramineum, 5,5-6 mm altum, 2-2,5 mm crassum. Bracteis involucralibus 14-15, hyalinis; externis ovatis, obtusis, 2,5-2,7 mm longis, 1,5-1,7 mm latis, dorso cum pilis lanosis grisis et albis, parce glandulosis, stereomate 1,5 $\mathrm{mm}$ alto; mediis ovato-oblongis vel lanceolatis, obtusis vel leviter acutis, 4,2-5 mm longis, 1,2$1,7 \mathrm{~mm}$ latis, dorso cum pilis lanosis et glandulosis, stereomate $1-2 \mathrm{~mm}$ alto; interioribus linear-oblongis, acutis, $5 \mathrm{~mm}$ longis, 0,8-1 mm latis, glabris, stereomate 2,8-3 mm alto. Flores straminei, dimorphi: marginales 3, feminei, corolla filiforme, 3,2-3,6 mm longa, apice 4dentata, dentibus deltoides, brevissimis, cum pilis glandulosis; stylo 3,5-4 mm longo; rami cum 0,5 mm, apice truncati, papillosi; flores disci 2-3, hermaphroditi, corolla tubulosa, 3,5 mm longa, 5-dentata, dentibus deltoides, 0,5 $\mathrm{mm}$ longis, cum pilis glandulosis; antherae 1,6-1,8 mm longae, caudatae; caudae elongatae, barbatae, apice oblongo-trigonae, subacutae. Achaenia oblonga, castanea, subcompressa, 0,9-1 mm longa, 0,3 mm lata. Pappus albus, setae 3,5-3,8 mm longae; cellulis apicalibus obtusis, basi patentibus.

Subarbusto ramoso, lenhoso, ascendente, densamente tomentoso, com ramos de $20-30 \mathrm{~cm}$ de comprimento (Figura 1a). Folhas alternas (entre-nós de 1-5 cm), sésseis, lanceoladas (3-9 $\mathrm{cm}$ de comprimento por 0,3-1 cm de largura), integras, discolores, densamente lanosotomentosas na parte abaxial, com ápice acuminado, base longo-atenuada e nervura

Artigo recebido em 24/05/2005 e aceito para publicação em 5/7/2005.

2 Biólogo, Msc., bolsista da CAPES, doutorando do Programa de Pós-Graduação em Engenharia Florestal, Centro de Ciências Rurais, Universidade Federal de Santa Maria, CEP 97105-900, Santa Maria (RS).deble.biol@bol.com.br

3 Engenheiro Florestal, Dr., bolsista de Produtividade em Pesquisa do CNPq, Professor Titular do Departamento de Ciências Florestais, Universidade Federal de Santa Maria, CEP 97105-900, Santa Maria (RS). balduinia@mail.ufsm.br

4 Dedicamos esta nova espécie ao botânico Osmar dos Santos Ribas, pelo envio do material-tipo. 


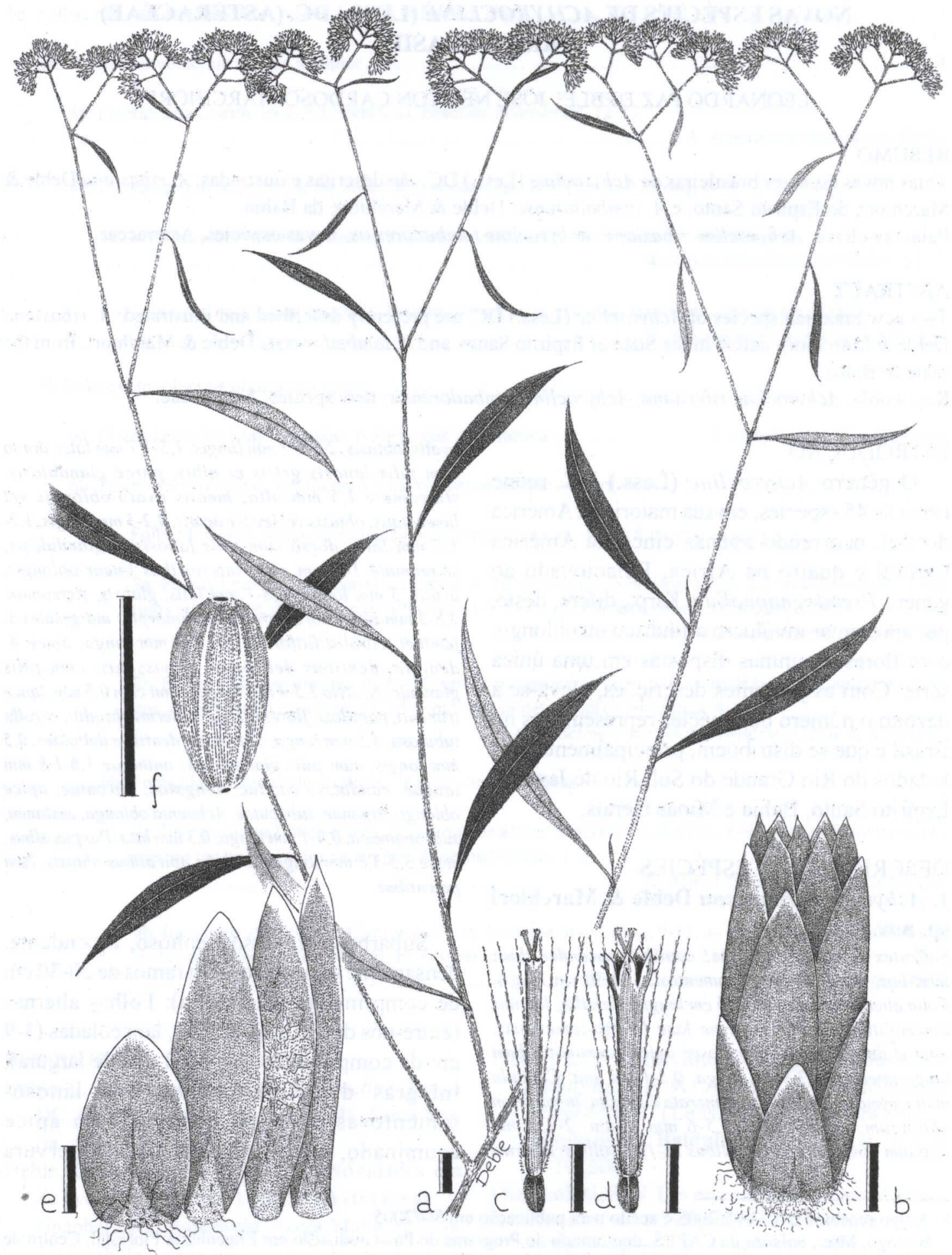

FIGURA 1 - Ramo de Achyrocline ribasiana (a). Capítulo (b). Flor marginal (c). Flor do disco (d). Brácteas involucrais (e). Aquênio (f). Escala a $=1 \mathrm{~cm} ; \mathrm{b}, \mathrm{c}, \mathrm{d}, \mathrm{e}, \mathrm{f}=1 \mathrm{~mm}$. 
central evidente (Figura 1a). Capítulos numerosos, em cimas de glomérulos, compondo panículas (Figura 1a). Invólucro oblongo, de cor paleácea, medindo 5,5-6 mm de altura por 2$2,5 \mathrm{~mm}$ de diâmetro (Figura $1 \mathrm{~b}$ ). Brácteas involucrais, 14-15; as externas, ovadas e obtusas no ápice, de 2,5-2,7 $\mathrm{mm}$ de comprimento por 1,5-1,7 $\mathrm{mm}$ de largura, com dorso coberto densamente de pêlos albos e gríseo-lanosos, escassos pêlos glandulares e estereoma de 1,5 $\mathrm{mm}$ de altura (Figura 1e); as medianas, ovadooblongas of lanceoladas $(4,2-5 \mathrm{~mm}$ de comprimento por 1,2-1,7 mm de largura) e obtusas no ápice, com pêlos lanosos e glandulares no dorso e estereoma de 1-2 mm de altura (Figura 1e); as internas, oblongo-lineares (5 mm de comprimento por $0,8-1 \mathrm{~mm}$ de largura), agudas no ápice e glabras, com estereoma de 2,8-3 $\mathrm{mm}$ de altura (Figura 1e). Flores estramíneas, dimorfas. As marginais, 3 , femininas e filiformes, com corola de 3,2-3,6 $\mathrm{mm}$ de comprimento e ápice 4-dentado (Figura 1c); dentes deltóides, brevíssimos, com pêlos glandulares (Figura 1c); estigma de 3,5-4 mm de comprimento, com ramas de $0,5 \mathrm{~mm}$, truncadas e papilosas no ápice. Flores do disco, $2-3$, hermafroditas, com corola de $3,5 \mathrm{~mm}$ de comprimento, 5-dentada no ápice (Figura 1d); dentes deltóides $(0,5 \mathrm{~mm})$, com pêlos glandulares (Figura 1d); anteras de 1,6-1,8 mm, com caudas fimbriadas, alongadas e ápice oblongo, triangular, levemente agudo. Aquênios oblongos, algo comprimidos, de 0,9-1 $\mathrm{mm}$ de comprimento por $0,3 \mathrm{~mm}$ de largura (Figura $1 \mathrm{f}$ ). Pápus branco, de 3,5-3,8 mm, com células apicais obtusas e células basais patentes.

TIPO - BRASIL, Espírito Santo, Cachoeira do Itapemirim, Vargem Alta, morro do Sal, arenícola, heliófila, flores alvas, folhas discolores, V. F. Ferreira 1847, 16.VIII.1981. Holotypus MBM.

Distribuição \& Habitat: Conhecida, até o momento, apenas para a localidade típica. Floresce no inverno.
Comentários: Espécie distinta pelas folhas lanceoladas e discolores, bem como pela forma e elevado número de brácteas involucrais. Aproxima-se de Achyrocline satureioides (Lam.) DC., do qual difere pelas folhas lanceoladas e discolores, pela forma das brácteas involucrais medianas e internas, pelas flores hermafroditas, com dentes de $0,5 \mathrm{~mm}$, bem como pelos aquênios glabros e angulosos. De Achyrocline flaccida (Weinm.) DC., Achyrocline peruviana Dillon \& Sagást. e Achyrocline tomentosa Rusby, separa-se principalmente pela forma e elevado número de brácteas involucrais.

\section{Achyrocline tombadorensis Deble \& Marchiori, sp. nov. ${ }^{5}$}

Suffrutex ramosus, lignosus, $2 \mathrm{~m}$ altus; caulibus ascendentibus, teretibus, ramosis, dense tomentosis. Folia alterna (internodiis 0,5-2 cm longis), sessilia, lanceolata, integra, trinervata, leviter discolor, dense lanosotomentosa, revoluta, apice acuta, basi attenuata, $2-6 \mathrm{~cm}$ longa, 0,3-1 cm lata. Capitula multa, dense cymosopaniculata glomerata disposita. Involucrum cylindraceum, stramineum, 5,5-6 mm altum, 1,5 mm crassum. Bracteis involucralibus 10-11, hyalinis; externis ovato-lanceolatis, acuminatis, 3,7-4 mm longis, 1,7 mm latis, dorso cum pilis lanosis et glandulosis, stereomate $1 \mathrm{~mm}$ alto; mediis lanceolatis, acuminatis, 4,5 mm longis, 0,8-1 mm latis, dorso cum pilis lanosis et glandulosis, stereomate 1,5-2 mm alto; interioribus lanceolatis, acuminatis, $5 \mathrm{~mm}$ longis, $1 \mathrm{~mm}$ latis, dorso cum pilis glandulosis, stereomate 2-2,5 mm alto. Flores dimorphi: marginales 3-4, feminei, corolla filiforme, 3,2 $\mathrm{mm}$ longa, apice 4-dentata, dentibus deltoides, brevissimis, cum pilis glandulosis; stylo 2,6-3 $\mathrm{mm}$ longo; rami cum 0,6 $\mathrm{mm}$, apice truncati, papillosi; flores disci 2, hermaphroditi, corolla tubulosa, $3 \mathrm{~mm}$ longa, 5-dentata, dentibus deltoides, 0,2 mm longis, cum pilis glandulosis; antherae 1,3 $\mathrm{mm}$ longae, caudatae; caudae elongatae, barbatae, apice oblongo-trigonae, subacutae. Achaenia ovata, castanea, glabra, 0,8 $\mathrm{mm}$ longa, 0,3 $\mathrm{mm}$ lata. Pappus albus, setae $3 \mathrm{~mm}$ longae; cellulis apicalibus subclavatis, basi patentibus.

Subarbusto ramoso, lenhoso, ascendente, densamente tomentoso, com cerca de $2 \mathrm{~m}$ de altura (Figura 2a). Folhas alternas (entrenós de

5 Uma referência ao local de procedência do materialtipo: a Serra do Tombador, no Estado da Bahia. 


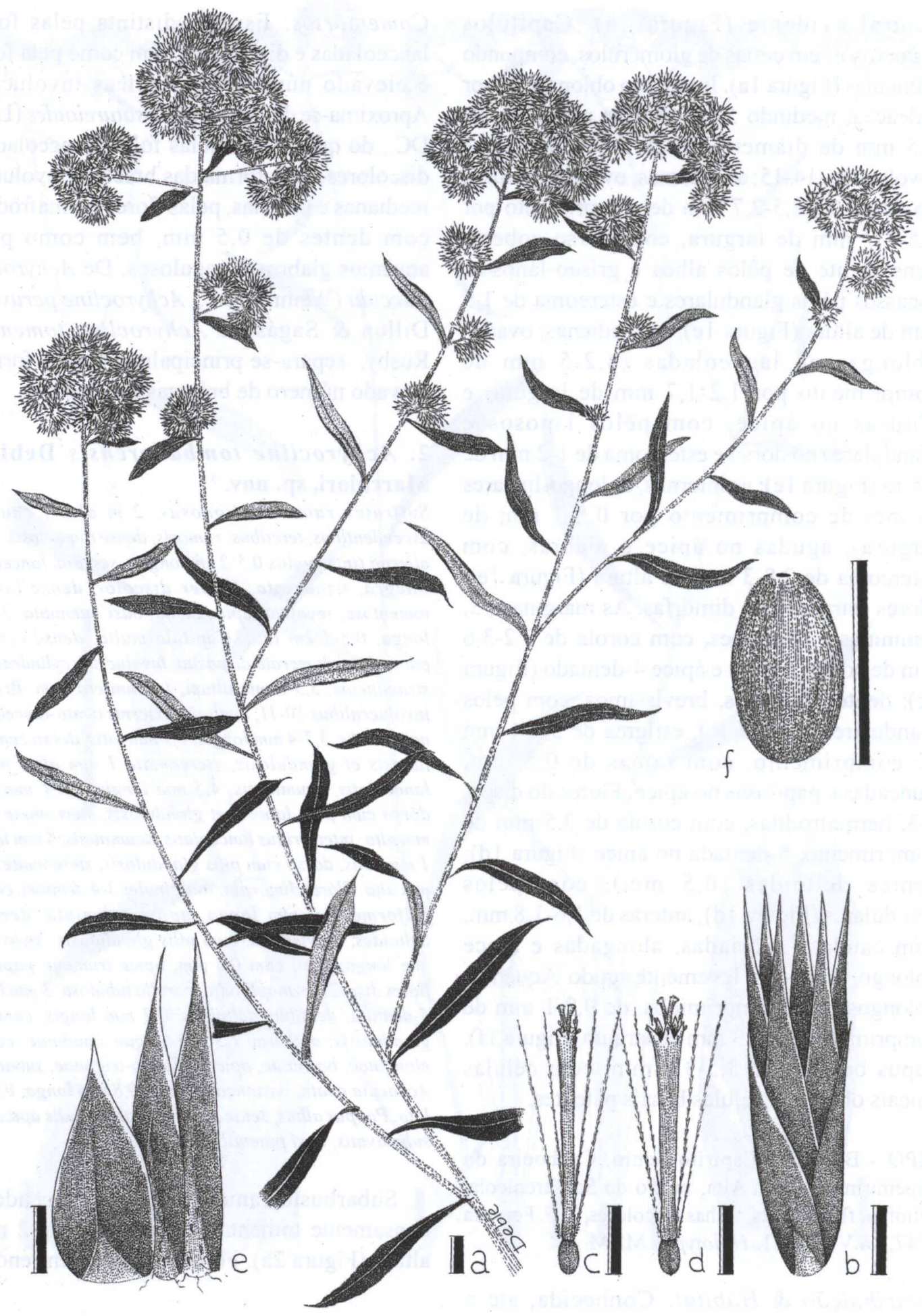

FIGURA 2 - Ramo de Achyrocline tombadorensis (a). Capítulo (b). Flor marginal (c). Flor do disco (d). Brácteas involucrais (e). Aquênio (f). Escala a $=1 \mathrm{~cm} ; \mathrm{b}, \mathrm{c}, \mathrm{d}, \mathrm{e}, \mathrm{f}=1 \mathrm{~mm}$. 
0,5-2 cm), sésseis, lanceoladas, trinervadas, íntegras, de 2-6 cm de comprimento por 0,3-1 cm de largura, discolores, de margens revolutas, densamente lanoso-tomentosas na parte abaxial e lanoso-tomentosas na parte adaxial, com ápice agudo e base atenuada (Figura 2a). Capítulos numerosos, estramíneos e dispostos em cimas de glomérulos, compondo panículas muito densas (Figura 2a). Invólucro cilíndrico, de 5,5-6 $\mathrm{mm}$ de altura por $1,5 \mathrm{~mm}$ de diâmetro (Figura 2b). Brácteas involucrais, 10-11; as externas, ovado-lanceoladas e acuminadas no ápice, com escassos pêlos lanosos e glandulosos de 3,7-4 $\mathrm{mm}$ de comprimento por $1,7 \mathrm{~mm}$ de largura, $\mathrm{e}$ estereoma de $1 \mathrm{~mm}$ de altura (Figura 2e); as medianas, lanceoladas ( $4,5 \mathrm{~mm}$ de comprimento por $0,8-1 \mathrm{~mm}$ de largura) e acuminadas no ápice, com pêlos lanosos e glandulares no dorso, e estereoma de 1,5-2 $\mathrm{mm}$ de altura (Figura $2 \mathrm{e}$ ); as internas, lanceoladas (5 $\mathrm{mm}$ de comprimento por $1 \mathrm{~mm}$ de largura) e acuminadas no ápice, com pêlos glandulares e lanosos no dorso, e estereoma de 2-2,5 mm de altura (Figura 2e). Flores dimorfas. As marginais, 3-4, femininas, filiformes, com corola de $3,2 \mathrm{~mm}$ de comprimento e ápice 4-dentado (Figura 2c); dentes deltóides, brevíssimos, com pêlos glandulares (Figura 2c); estigma de 2,6-3 mm de comprimento, com ramas de 0,6 $\mathrm{mm}$, truncadas e papilosas no ápice. Flores do disco, 2, hermafroditas, com corola de 3 $\mathrm{mm}$ de comprimento, 5-dentada no ápice (Figura $2 \mathrm{~d})$; dentes deltóides $(0,2 \mathrm{~mm})$, com pêlos glandulares (Figura 2d); anteras de 1,3 mm, com caudas fimbriadas, alongadas e ápice oblongo, triangular, levemente agudo. Aquênios ovados, glabros, de $0,8 \mathrm{~mm}$ de comprimento por $0,3 \mathrm{~mm}$ de largu- ra (Figura 2f). Pápus branco, de $3 \mathrm{~mm}$, com células apicais subclavadas e células basais patentes.

TIPO - BRASIL, Bahia, Jacobina, Serra do Tombador, estrada de Jacobina para morro do Chapéu, cerca de $24 \mathrm{~km}$ a partir da sede do município, campo rupestre, A. M. A. Amorim, A. M. V. Carvalho, S. C. Sant'Ana, J. G. Jardim \& G. V. F. Pitanga 1815, 28.X.1995. Holotypus MBM. Isotypus CEPEC.

Distribuição \& Habitat: Conhecida apenas para a Serra do Tombador (Bahia). Floresce durante a primavera.

Comentários: Espécie próxima de Achyrocline polycephala Rusby ( $=$ ? tomentosa), pela forma das folhas e densa inflorescência; difere, todavia, pelo invólucro maior, bem como pela forma e maior número de brácteas involucrais. Das demais espécies brasileiras, separa-se pelas brácteas involucrais acuminadas no ápice e pela inflorescência em panículas muito densas.

\section{BIBLIOGRAFIA}

Deble, L. P., Marchiori, J. N. C. Novidades em Achyrocline (Less.) DC. (AsteraceaeGnaphalieae). Balduinia, Santa Maria, n. 3, p. 10-13, 2005.

Dillon M. O., Sagástegui, A. A new species of Achyrocline (Inuleae-Asteraceae) from Peru. Phytologia, New York, v. 60, n. 2, p. 106-110, 1986.

Giangualani, R. N. Las especies argentinas del género Achyrocline (Compositae). Darwiniana, San Isidro, v. 20, n. 3-4, p. 549-576, 1976.

Hind, D. J. N. Notes on the Compositae of Bahia, Brazil: I. Kew Bull., Kew, v. 48, n. 2, p. 254257, 1993. 